\title{
Serum glucose as an important predictor of delayed cerebral ischemia in angiogram-negative subarachnoid hemorrhage
}

\section{Zeyu Zhang}

Zhejiang University School of Medicine Second Affiliated Hospital

Anke Zhang

Zhejiang University School of Medicine Second Affiliated Hospital

\section{Xiaoyu Wang}

Zhejiang University School of Medicine Second Affiliated Hospital

\section{Yuanjian Fang}

Zhejiang University School of Medicine Second Affiliated Hospital

Yibo Liu

Zhejiang University School of Medicine Second Affiliated Hospital

\section{Yujie Luo}

Zhejiang University School of Medicine Second Affiliated Hospital

\section{Cameron Lenahan}

Loma Linda University School of Medicine

Sheng Chen ( $\nabla$ saintchan@zju.edu.cn )

Zhejiang University School of Medicine Second Affiliated Hospital https://orcid.org/0000-0002-8374136X

\section{Jianmin Zhang}

Zhejiang University School of Medicine Second Affiliated Hospital

\section{Research}

Keywords: Angiogram-negative subarachnoid hemorrhage, Delayed cerebral ischemia, Serum glucose, Hyperglycemia, Biomarker

Posted Date: February 24th, 2021

DOI: https://doi.org/10.21203/rs.3.rs-250603/v1

License: (c) (i) This work is licensed under a Creative Commons Attribution 4.0 International License. Read Full License 


\section{Abstract \\ Background}

Despite benign overall course, angiogram-negative subarachnoid hemorrhage (AN-SAH) still companies with risk of delayed cerebral ischemia $(\mathrm{DCl})$. Serum glucose was previously found to be related to $\mathrm{DCl}$ occurrence in aneurysmal subarachnoid hemorrhage (aSAH), but this has not been confirmed in AN-SAH. The aim of this study was to clarify the significance of serum glucose in $\mathrm{DCl}$ prediction in AN-SAH patients.

\section{Methods}

We included patients with AN-SAH admitted to our hospital between January 2013 and December 2018. According to different bleeding patterns, patients were divided into perimesencephalic AN-SAH (PAN-SAH) and non-perimesencephalic AN-SAH (NPAH-SAH) patients. DCl was defined as symptomatic vasospasm or/and delayed cerebral infarction. A statistical analysis of the clinical, radiological, and laboratory risk factors of $\mathrm{DCl}$ was conducted. Logistic regression analysis was performed to identify the independent predictors of $\mathrm{DCl}$.

\section{Results}

A total of 244 AN-SAH patients (mean age 55.7 years, $55.7 \%$ men) were included with $164(67.2 \%)$ PANSAH patients and 80 (32.8\%) NPAN-SAH patients. There were significant correlations between high DCI incidence and high serum glucose levels in the first five days after admission in both PAN-SAH patients and NPAN-SAH patients $(p<0.05)$. High admission serum glucose was significantly related to higher World Federation of Neurosurgeons Scale (WFNS) $(p<0.05)$. Multivariate logistic regression analysis showed that admission serum glucose $(p=0.001$, OR 1.705, 95\% Cl 1.232-2.360) and WFNS $(p=0.008$, OR 2.889, 95\% Cl 1.322-6.311) were both significant and independent predictors for $\mathrm{DCl}$ occurrence in PAN-SAH patients. Admission serum glucose $(p=0.016$, OR 2.307, 95\% $\mathrm{Cl} 1.167-4.562)$, standard deviation (SD) of the serum glucose in the first three days after admission ( $p=0.049,0 R 5.684,95 \% \mathrm{Cl}$ $1.006-32.114)$ and modified Fisher scale ( $\mathrm{mFS})(p=0.033$, OR 1.859, 95\% Cl 1.051-3.288) were significant and independent predictors for $\mathrm{DCl}$ occurrence in NPAN-SAH patients.

\section{Conclusions}

Serum glucose is an early biomarker to predict DCl risk in both PAN-SAH and NPAN-SAH patients, which has an important value in guiding intensive care in AN-SAH patients.

\section{Background}


Despite repeated cerebral angiography, the source of bleeding cannot be identified in approximately $15 \%$ of patients with spontaneous subarachnoid hemorrhage (SAH). This subgroup has been classified as angiogram-negative SAH (AN-SAH) [1-3]. According to different bleeding patterns shown on computed tomography (CT), AN-SAH is divided into perimesencephalic AN-SAH (PAN-SAH) and nonperimesencephalic AN-SAH (NPAH-SAH) [4]. It was previously believed that AN-SAH has a different natural history and better outcome compared to aneurysmal SAH (aSAH). However, recent studies have shown that the clinical course and outcome of NPAN-SAH are similar to that of aSAH [5]. Although the overall course is relatively benign, AN-SAH still has a certain incidence of delayed cerebral ischemia (DCl) and poor outcome, particularly in NPAN-SAH patients [5]. Therefore, it is important to find early risk factors that predict $\mathrm{DCl}$ and unfavorable outcome for patients with AN-SAH.

Previous studies have confirmed the clinical value of several biomarkers for $\mathrm{DCl}$ after aSAH, such as serum glucose, lactate, D-dimer, C-reactive Protein (CRP), and white blood cell (WBC) count [6-8]. However, few studies have focused on the risk factors of DCl in patients with AN-SAH. Previous studies found that hyperglycemia at admission was associated with increased short-term mortality in aSAH patients without diabetes [9]. Moreover, another study found a correlation between early serum glucose levels and the occurrence of $\mathrm{DCl}$ and poor outcome in patients with aSAH [6]. In addition, serum glucose variability during hospitalization was also confirmed to be related to mortality, delayed cerebral infarction and neurological outcome after aSAH [10-12]. However, there was no study exploring the clinical value and predictive role of serum glucose levels in AN-SAH.

In this study, we analyzed our institutional data to illustrate the relationship between serum glucose and risk of $\mathrm{DCl}$ occurrence, and we investigated whether early serum glucose could be a predictor of $\mathrm{DCl}$ in AN-SAH.

\section{Methods}

\section{Study population}

In this study, consecutive patients with AN-SAH admitted to the Second Affiliated Hospital, School of Medicine, Zhejiang University, between January 1, 2013 and December 31, 2018 were retrospectively reviewed. All patients were admitted to the hospital within 24 hours after onset. AN-SAH was defined as non-traumatic SAH with negative findings in the first cerebral digital subtraction angiography (DSA) examination, which was performed according to strict standards within 72 hours of admission [4]. Some patients underwent a repeated DSA examination 10-14 days later. In addition, the following patients were excluded: (1) history of head injury or suspicious head injury; (2) history of previous diabetes; (3) missing/lost radiological data; (4) missing/lost serum glucose data on admission or during hospitalization.

All aspects of this study were approved by the local Institutional Review Board. Due to the approval of the Institutional Review Board, patient consent was not required in this study. 


\section{Patient management}

All patients were diagnosed as AN-SAH by CT and DSA performed at admission. According to different bleeding patterns, AN-SAH was divided into PAN-SAH and NPAN-SAH $[4,13,14]$. The characteristics of PAN-SAH are as follows: (1) hemorrhage anterior to the midbrain and/or pons; (2) no extension into parenchyma or ventricle; (3) no complete extension into the anterior interhemispheric fissure; (4) possible extension into the basal parts of the sylvian fissures, but not into the lateral sylvian fissures; (5) no significant intraventricular hemorrhage. Those that did not meet the bleeding pattern described above were classified as NPAN-SAH.

We reviewed the baseline characteristics of the patients, including age, gender, past medical history, social history, hospital stay, and body mass index (BMI). The clinical and radiological data obtained during hospitalization were used to assess the severity of SAH. The clinical data included the World Federation of Neurosurgeons Scale (WFNS) and Hunt and Hess $(\mathrm{HH})$ grade $[15,16]$. The radiological data included the modified Fisher scale (mFS), Subarachnoid Hemorrhage Early Brain Edema Score (SEBES), and intraventricular hemorrhage (IVH) $[17,18]$. Additionally, we investigated the laboratory data on admission, including sodium, potassium, glucose, total cholesterol (TC), triglyceride (TG), high-density lipoprotein cholesterol (HDL-C), low-density lipoprotein cholesterol (LDL-C), apolipoprotein A1 (ApoA1), and apolipoprotein $B(A p o B)$. We reviewed the serum glucose levels in the first 5 days after admission. All the patients had at least one arterial glucose measurement per day for the first 3 days after admission, and at least one measurement on days 4 and 5 . If the serum glucose was measured multiple times in one day, the median measurement would be used for that daily value. Moreover, SAH-related complications, such as rebleeding, acute hydrocephalus, seizure, and DCI were also reviewed [19-21].

All patients were treated in accordance with SAH guidelines provided by the Neurocritical Care Society and the American Heart Association [22, 23]. Hemodynamic values were monitored via electrocardiogram on admission. All patients received nimodipine and intravenous hydration to prevent cerebral vasospasm and maintain euvolemia, respectively.

\section{Outcome assessment}

This study defined outcomes in terms of the occurrence of $\mathrm{DCl}$. $\mathrm{DCl}$ was defined as symptomatic vasospasm and/or delayed cerebral infarction. Symptomatic vasospasm was diagnosed as a focal neurological impairment or decrease of at least 2 points on the Glasgow Coma Scale (GCS) lasting for at least 1 hour, is not immediately apparent after SAH onset, and is not attributable to other causes [24]. Delayed cerebral infarction referred to a new infarction emerging on CT or magnetic resonance imaging (MRI), which was not present within the first 24 to 48 hours after SAH onset, and was not attributable to other causes [24]. Two senior neurologists independently evaluated all the radiological data. If there was a divergence between the two neurologists, a third examiner would be used.

\section{Statistical analysis}


Statistical analysis was performed using IBM-SPSS V24.0 (SPSS Inc, Armonk, NY) and Prism 8 (GraphPad Software, Inc, LA Jolla, CA). All p-values were two-tailed with statistical significance set at pvalue $<0.05$. Demographic data, clinical data, radiological data, laboratory data, and SAH-related complications were compared between the DCl and the non-DCI groups. The Shapiro-Wilk test was used to evaluate normality of the data. Normally and abnormally distributed variables were respectively expressed as means \pm standard deviations (SD), as well as median and interquartile range (IQR). Categorical variables were expressed as the number of patients (percentage). Student's t-test was used to compare the normally distributed variables. Mann-Whitney U-test was used to compare the non-normally distributed variables. Chi-square or Fisher's exact test was used to compare the categorical variables. Subsequently, the variables of PAN-SAH and NPAN-SAH patients were compared. After dividing AN-SAH patients into PAN-SAH patients and NPAN-SAH patients, the variables between the DCl group and non-DCl group were compared again. In addition, the characteristics of the high glucose and the low glucose groups were compared. Finally, univariate and multivariate binary logistic regression analysis were performed. The odds ratio (OR) and 95\% confidence interval (Cl) were calculated. Multivariate logistic regression analysis, using a backward selection method, was performed for the variables with a p-value < 0.15 in univariate analysis to identify the independent predictors of $\mathrm{DCl}$.

\section{Results}

\section{Patient characteristics}

A total of 296 patients were diagnosed with AN-SAH. Thirteen patients had a history of head injury or suspicion of head injury. Twenty-two patients suffered from diabetes. Ten patients were missing radiological data and seven patients were missing serum glucose data on admission or during hospitalization. Therefore, 244 patients were included in the final cohort, with 164 (67.2\%) PAN-SAH patients and 80 (32.8\%) NPAN-SAH patients. Males comprised 136 (55.7\%) of the patients. The average age of the patients was 55.7 years.

According to the occurrence of $\mathrm{DCl}, 244 \mathrm{AN}-\mathrm{SAH}$ patients were divided into $\mathrm{DCl}$ group $(\mathrm{n}=62)$ and non$\mathrm{DCl}$ group $(\mathrm{n}=182)$. There were significant correlations between the $\mathrm{DCl}$ group and age $(p=0.045)$, hypertension $(p=0.021)$, hospital stay $(p<0.001)$, ICU stay $(p<0.001)$, PAN $(p<0.001)$, WFNS $(p<$ $0.001)$, HH grade $(p<0.001)$, mFS ( $p<0.001)$, SEBES $(p<0.001)$, IVH $(p<0.001)$, rebleeding $(p<0.001)$, acute hydrocephalus $(p<0.001)$, and admission serum glucose $(p<0.001$; Table 1$)$.

\section{Comparison of variables between PAN-SAH and NPAN-SAH patients}

The evaluation of associations regarding bleeding patterns with patient characteristics is shown in Table 2. Hospital stay, WFNS, HH grade, mFS, SEBES, IVH, and admission serum glucose presented significant differences between PAN-SAH patients and NPAN-SAH patients (all $p<0.001$ ). Additionally, there were significant differences in some complications, including $\mathrm{DCl}(\mathrm{p}<0.001)$, rebleeding $(\mathrm{p}=0.001)$, and acute hydrocephalus $(p<0.001)$ between the two populations. 


\section{Comparison of variables between $\mathrm{DCl}$ and non- $\mathrm{DCl}$ groups in two bleeding patterns}

Due to the significant differences in the characteristics between two bleeding patterns, we analyzed the data of PAN-SAH and NPAN-SAH patients (Table 3). The DCl group was still significantly associated with high admission serum glucose in both populations (both $p<0.001$; Fig. $1 \mathrm{~A}, \mathrm{~B}$ ). There was a significant association between high SD of serum glucose in the first three days and DCl group in both PAN-SAH $(p=$ 0.038; Fig. 1C) and NPAN-SAH ( $p=0.001$; Fig. 1D) patients. In addition, there were significant correlations between the DCl group and an extended stay in the hospital and ICU stay, as well as high WFNS, high HH grade, high $\mathrm{mFS}, \mathrm{IVH}$, and high serum glucose in the first five days after admission in both PAN-SAH patients and NPAN-SAH patients (all $p<0.05$ ).

\section{Dynamic changes of serum glucose after admission}

Serum glucose levels of $\mathrm{DCl}$ and non-DCl groups showed similar trends after admission in both PAN-SAH (Fig. 2A) and NPAN-SAH (Fig. 2B) patients. Shortly after admission, the serum glucose levels gradually decreased and reached the lowest value on the third day. However, in the four or five days after admission, glucose levels increased slightly. In both bleeding patterns, the serum glucose of the DCI group was consistently higher than that of the non-DCl group in the first five days after admission.

\section{Comparison of variables between high and low glucose groups in two bleeding patterns}

We then divided the PAN-SAH patients and the NPAN-SAH patients into either high or low glucose groups according to the median serum glucose on admission of each group $(6.575 \mathrm{mmol} / \mathrm{L}$ in PAN-SAH patients and $7.235 \mathrm{mmol} / \mathrm{L}$ in NPAN-SAH patients). The results are shown in Additional file 1: Table S1. In the PAN-SAH population, patients in the high glucose group had higher age $(p=0.036)$, WFNS $(p<0.001), \mathrm{HH}$ grade $(p=0.004)$, and DCl incidence $(p=0.003)$. In the NPAN-SAH population, patients in the high glucose group had an extended hospital stay $(p=0.009)$, as well as high WFNS $(p=0.004)$ and increased incidence of $\mathrm{DCl}(p<0.001)$ and acute hydrocephalus $(p=0.039)$. The distributions of WFNS, HH grade, $\mathrm{mFS}, \mathrm{SEBES}$, and DCl in the two groups are shown in Additional file 2: Figure S1. The percentages of patients with high WFNS, HH grade, mFS, SEBES, and DCl incidence were often higher in the high glucose group than in the low glucose group.

\section{Multivariate analysis of predictors for DCl in PAN-SAH and NPAN-SAH patients}

The results of univariate and multivariate analyses concerning variables that influence the occurrence of DCI in PAN-SAH and NPAN-SAH patients are provided in Table 4. Multivariate logistic regression analysis revealed admission serum glucose $(p=0.001$, OR $1.705,95 \% \mathrm{Cl} 1.232-2.360)$ and WFNS $(p=0.008$, OR $2.889,95 \% \mathrm{Cl} 1.322-6.311)$ as significant and independent predictors for the occurrence of DCl in PANSAH patients. Admission serum glucose $(p=0.016,0 R 2.307,95 \% \mathrm{Cl} 1.167-4.562)$ and SD of the serum glucose in the first three days after admission $(p=0.049$, OR 5.684, 95\% Cl 1.006-32.114) and $\mathrm{mFS}(\mathrm{p}=$ 0.033, OR 1.859, 95\% Cl 1.051-3.288) were significant and independent predictors for the occurrence of DCl in NPAN-SAH patients. 


\section{Discussion}

The main findings of our study were that high early serum glucose levels significantly correlated with high incidence of DCl in both PAN-SAH and NPAN-SAH patients, despite similar time-dependent changes in $\mathrm{DCl}$ and non-DCl groups. In addition, high serum glucose levels on admission were associated with high WFNS. Multivariate logistic regression analysis showed that admission serum glucose was a significant and independent predictor for DCl occurrence in both PAN-SAH and NPAN-SAH patients. To our knowledge, this is the first article to illustrate the association of serum glucose and occurrence of $\mathrm{DCl}$ after AN-SAH.

AN-SAH occurs in approximately $15 \%$ of SAH patients, and is characterized as either PAN-SAH or NPANSAH according to their bleeding patterns [3]. Although the overall prognosis is good, a certain percentage of AN-SAH patients still have $\mathrm{DCl}$ and poor outcome, especially NPAN-SAH $[4,5]$. It is generally believed that patients with NPAN-SAH have a worse neurological outcome and a higher incidence of complications than PAN-SAH patients, which is consistent with our findings [3,25]. The prognosis of NPAN-SAH is considered similar to that of aSAH [5]. Therefore, it is necessary to identify early risk factors of $\mathrm{DCl}$ and unfavorable outcome in AN-SAH. However, few studies have focused on factors related to the occurrence of $\mathrm{DCl}$ in AN-SAH patients thus far.

Previous studies have verified the relationship between serum glucose and $\mathrm{DCl}$ or vasospasm after aSAH. One study found that post-aSAH symptomatic vasospasm significantly correlated with admission serum glucose levels $(p=0.003)$, which was congruent with our findings. However, in multivariate analysis, admission glucose levels were not a significant predictor of symptomatic vasospasm (OR, $0.99[95 \% \mathrm{Cl}$, 0.99-1.01]) [26]. In another study, maximum serum glucose levels shortly after aSAH were associated with an increased risk of $\mathrm{DCl}(p=0.002)$. Multivariate analysis showed that glucose was an independent predictor of $\mathrm{DCl}(\mathrm{OR}, 1.17$ [95\% Cl, 1.05-1.30]) [6]. This is consistent with the results we found in patients with AN-SAH. However, this study differs in that it defined $\mathrm{DCl}$ as a new hypodensity on $\mathrm{CT}$ not otherwise explained by cerebral infarction due to $\mathrm{DCl}$ after admission. To more accurately understand the relationship between serum glucose and $\mathrm{DCl}$ after $\mathrm{AN}-\mathrm{SAH}$, we also analyzed the mean, maximum, minimum, range, SD, and CV of serum glucose shortly after admission. In addition, another study found that the serum glucose/potassium ratio was an independent predictor of cerebral vasospasm after aSAH [27].

Although the mechanisms underlying the relation between serum glucose and risk of $\mathrm{DCl}$ are still unclear, the SAH-induced stress response may explain this association. Catecholamines, glucagon, and corticosteroids are the main hormones involved in causing hyperglycemia [27]. Neurogenic stress can cause the release of these hormones, which may induce inflammation and cause systemic damage [28]. Elevation of serum catecholamine concentrations, which induce sympathetic activation, has been confirmed after aSAH, and was found to be associated with a poor outcome [29]. One study found that early sympathetic activation after bleeding reflected the severity of aSAH, and was related to the development of $\mathrm{DCl}$ and poor outcomes [30]. A cohort study showed that using a beta-blocker to inhibit 
sympathetic activity was associated with a lower incidence of cerebral vasospasm in patients with aSAH [31]. An experimental study also confirmed the correlation between sympathetic suppression and decreased cerebral vasospasm after SAH [32]. Therefore, elevated serum glucose after SAH may reflect the stress response and severity of the neurological insult. In the present study, patients with higher serum glucose on admission showed had increased severity when assessed using WFNS, as well as increased risk of DCI. NPAN-SAH patients have higher serum glucose levels, as well as higher clinical and radiological severity than PAN-SAH patients. This may reflect that NPAN-SAH patients have a stronger stress response and more severe neurological damage when compared with PAN-SAH patients, and may explain the higher risk of DCl in patients with NPAN-SAH. However, after controlling for some risk factors, including WFNS and mFS, the admission serum glucose was still associated with the occurrence of DCl, suggesting that there might be other mechanisms mediating the link between serum glucose and risk of $\mathrm{DCl}$.

It remains unclear whether hyperglycemia plays a role in the occurrence of $\mathrm{DCl}$ or if it is just a stress response to SAH. Previous studies have shown that hyperglycemia may exacerbate secondary brain injury after stroke [33]. Moreover, hyperglycemia provides an abundant substrate for anaerobic glycolysis in ischemic brain tissue, which leads to excessive lactate accumulation, acidosis, and cell death [34]. In a rat SAH model, hyperglycemia exacerbated cerebral vasospasm by dysregulating endothelial nitric oxide synthase (eNOS) and inducing nitric oxide synthase (iNOS) [35]. Another experimental study indicated that hyperglycemia may activate the extrinsic caspase cascade through the extracellular regulated kinase (ERK) signal pathway to contribute to neuronal apoptosis after SAH [36]. Aggressive glucose management may help improve outcome in aSAH [33]. However, some studies held an opposite view. A previous prospective study found that hyperglycemia preceded aSAH onset, as evidenced by the elevated glycated hemoglobin (HbA1c) levels, but did not lead to poor outcome [37]. Low cerebral glucose, which is related to severe metabolic distress, may exert deleterious effects in patients with aSAH [38]. Intensive glycemic control with insulin after aSAH may reduce cerebral glucose, leading to worse outcome $[39,40]$. However, some studies have shown that increasing serum glucose through enteral nutrition could increase cerebral glucose levels without causing abnormal cerebral glucose metabolism, which may improve the prognosis of patients with aSAH [41, 42]. Therefore, post-SAH hyperglycemia may be a protective factor in the brain that compensates for insufficient cerebral glucose after brain injury.

Our study is the first to examine the relationship between early serum glucose levels and risk of $\mathrm{DCl}$ in patients with AN-SAH. In this study, high serum glucose at admission correlated with high WFNS, indicating that admission serum glucose may reflect the severity of AN-SAH. Serum glucose levels at admission and early after admission, which may reflect the degree of SAH-induced stress, were significantly associated with the occurrence of DCI in both PAN-SAH patients and NPAN-SAH patients. Multivariate analysis showed that admission serum glucose was an independent predictor of $\mathrm{DCl}$ risk after PAN-SAH or NPAN-SAH. Since serum glucose is routinely collected in SAH patients, it seems to be a convenient method to identify patients at high risk of $\mathrm{DCl}$ after AN-SAH to guide intensive care. It remains unclear whether the elevated serum glucose after AN-SAH has a harmful effect. Therefore, tight glycemic control is not recommended. 
Several limitations of this study should be considered. First, we did not study stress-related indicators after AN-SAH. Other parameters must be collected to further establish the relationship between serum glucose and DCl risk. Second, due to the mild condition and short hospital stay of AN-SAH patients, we only collected the serum glucose data in the first five days after admission. In addition, glucose infusion, diet, drug use, and number of glucose measurements during hospitalization were not taken into account as a potential confounder, which may have introduced bias. Third, potential bias may exist in how $\mathrm{DCl}$ is defined. To address this problem, we defined the $\mathrm{DCl}$ according to the criteria of the previous study [24]. Two senior neurologists who were blind to the clinical information independently evaluated the DCl. Additionally, we did not record the specific time when the patients developed DCl. Fourth, because patients with missing radiological and serum glucose data often have better neurological status at admission, our results likely apply to patients in a moderately worse condition at admission. Finally, our study was retrospective and conducted at a single center. A multicenter collaborative prospective validation with an increased cohort size is recommended in future studies.

\section{Conclusions}

Among patients with PAN-SAH or NPAN-SAH, those with higher early serum glucose tend to have more severe conditions and a higher incidence of $\mathrm{DCl}$. Admission serum glucose is an independent predictor of the occurrence of DCl after PAN-SAH or NPAN-SAH, which can serve as an early biomarker to predict DCI risk, and may guide intensive care in AN-SAH patients. Further studies with larger cohorts are needed to verify our findings.

\section{Abbreviations}

SAH: subarachnoid hemorrhage; AN-SAH: angiogram-negative subarachnoid hemorrhage; CT: computed tomography; PAN-SAH: perimesencephalic angiogram-negative subarachnoid hemorrhage; NPAH-SAH: non-perimesencephalic angiogram-negative subarachnoid hemorrhage; aSAH: aneurysmal subarachnoid hemorrhage; DCl: delayed cerebral ischemia; CRP: C-reactive Protein; WBC: white blood cell; DSA: digital subtraction angiography; BMI: body mass index; WFNS: World Federation of Neurosurgeons Scale; $\mathrm{HH}$ : Hunt and Hess; mFS: modified Fisher scale; SEBES: Subarachnoid Hemorrhage Early Brain Edema Score; IVH: intraventricular hemorrhage; TC: total cholesterol; TG: triglyceride; HDL-C: high-density lipoprotein cholesterol; LDL-C: low-density lipoprotein cholesterol; ApoA1: apolipoprotein A1; ApoB: apolipoprotein B; GCS: Glasgow Coma Scale; MRI: magnetic resonance imaging; SD: standard deviation; IQR: interquartile range; OR: odds ratio; $\mathrm{Cl}$ : confidence interval; eNOS: endothelial nitric oxide synthase; iNOS: inducing nitric oxide synthase; ERK: extracellular regulated kinase; $\mathrm{HbA1c}$ : glycated hemoglobin

\section{Declarations}

\section{Acknowledgements}

Not applicable. 


\section{Authors' contributions}

ZYZ designed the study and wrote the manuscript; AKZ and XYW collected the study data; YJF, AKZ, JMZ, and $\mathrm{CL}$ revised the manuscript; YBL, YJL, and SC participated in the design and coordination of the study. All authors read and approved the final version of the manuscript.

\section{Funding}

This research was supported by the National Natural Science Foundation of China (No. 81870916 and No. 81971107).

\section{Availability of data and materials}

The data is not available because of patients' privacy.

\section{Ethics approval and consent to participate}

This retrospective study was approved by the institutional review board of the Second Affiliated Hospital of Zhejiang University School of Medicine. The requirement for written informed consent was waived due to its retrospective nature.

\section{Consent for publication}

Not applicable.

\section{Competing interests}

The authors declare that they have no competing interests.

\section{References}

1. Jung JY, Kim YB, Lee JW, Huh SK, Lee KC. Spontaneous subarachnoid haemorrhage with negative initial angiography: a review of 143 cases. J Clin Neurosci. 2006;13(10):1011-1017.

2. Lin N, Zenonos G, Kim AH, Nalbach SV, Du R, Frerichs KU, et al. Angiogram-negative subarachnoid hemorrhage: relationship between bleeding pattern and clinical outcome. Neurocrit Care. 2012;16(3):389-398.

3. Boswell S, Thorell W, Gogela S, Lyden E, Surdell D. Angiogram-negative subarachnoid hemorrhage: outcomes data and review of the literature. J Stroke Cerebrovasc Dis. 2013;22(6):750-757.

4. Fang Y, Shao A, Wang X, Lu J, Wu H, Ren R, et al. Deep venous drainage variant rate and degree may be higher in patients with perimesencephalic than in non-perimesencephalic angiogram-negative subarachnoid hemorrhage. Eur Radiol. 2020.

5. Al-Mufti F, Merkler AE, Boehme AK, Dancour E, May T, Schmidt JM, et al. Functional Outcomes and Delayed Cerebral Ischemia Following Nonperimesencephalic Angiogram-Negative Subarachnoid 
Hemorrhage Similar to Aneurysmal Subarachnoid Hemorrhage. Neurosurgery. 2018;82(3):359-364.

6. van Donkelaar CE, Dijkland SA, van den Bergh WM, Bakker J, Dippel DW, Nijsten MW, et al. Early Circulating Lactate and Glucose Levels After Aneurysmal Subarachnoid Hemorrhage Correlate With Poor Outcome and Delayed Cerebral Ischemia: A Two-Center Cohort Study. Crit Care Med. 2016;44(5):966-972.

7. Hurth H, Birkenhauer U, Steiner J, Schlak D, Hennersdorf F, Ebner FH. Delayed Cerebral Ischemia in Patients with Aneurysmal Subarachnoid Hemorrhage - Serum D-dimer and C-reactive Protein as Early Markers. J Stroke Cerebrovasc Dis. 2020;29(3):104558.

8. Al-Mufti F, Misiolek KA, Roh D, Alawi A, Bauerschmidt A, Park S, et al. White Blood Cell Count Improves Prediction of Delayed Cerebral Ischemia Following Aneurysmal Subarachnoid Hemorrhage. Neurosurgery. 2019;84(2):397-403.

9. Lee SH, Lim JS, Kim N, Yoon BW. Effects of admission glucose level on mortality after subarachnoid hemorrhage: a comparison between short-term and long-term mortality. J Neurol Sci. 2008;275(12):18-21.

10. Kurtz P, Claassen J, Helbok R, Schmidt J, Fernandez L, Presciutti M, et al. Systemic glucose variability predicts cerebral metabolic distress and mortality after subarachnoid hemorrhage: a retrospective observational study. Crit Care. 2014;18(3):R89.

11. Barletta JF, Figueroa BE, DeShane R, Blau SA, McAllen KJ. High glucose variability increases cerebral infarction in patients with spontaneous subarachnoid hemorrhage. J Crit Care. 2013;28(5):798-803.

12. Okazaki T, Hifumi T, Kawakita K, Shishido H, Ogawa D, Okauchi M, et al. Blood Glucose Variability: A Strong Independent Predictor of Neurological Outcomes in Aneurysmal Subarachnoid Hemorrhage. J Intensive Care Med. 2018;33(3):189-195.

13. Song JH, Yeon JY, Kim KH, Jeon P, Kim JS, Hong SC. Angiographic analysis of venous drainage and a variant basal vein of Rosenthal in spontaneous idiopathic subarachnoid hemorrhage. $\mathrm{J}$ Clin Neurosci. 2010;17(11):1386-1390.

14. Mortimer AM, Appelman AP, Renowden SA. The negative predictive value of CT angiography in the setting of perimesencephalic subarachnoid hemorrhage. J Neurointerv Surg. 2016;8(7):728-731.

15. Rosen DS, Macdonald RL. Grading of subarachnoid hemorrhage: modification of the world World Federation of Neurosurgical Societies scale on the basis of data for a large series of patients. Neurosurgery. 2004;54(3):566-575; discussion 575-566.

16. Hunt WE, Hess RM. Surgical risk as related to time of intervention in the repair of intracranial aneurysms. J Neurosurg. 1968;28(1):14-20.

17. Frontera JA, Claassen J, Schmidt JM, Wartenberg KE, Temes R, Connolly ES, Jr., et al. Prediction of symptomatic vasospasm after subarachnoid hemorrhage: the modified fisher scale. Neurosurgery. 2006;59(1):21-27; discussion 21-27.

18. Ahn SH, Savarraj JP, Pervez M, Jones W, Park J, Jeon SB, et al. The Subarachnoid Hemorrhage Early Brain Edema Score Predicts Delayed Cerebral Ischemia and Clinical Outcomes. Neurosurgery. 2018;83(1):137-145. 
19. Macdonald RL, Schweizer TA. Spontaneous subarachnoid haemorrhage. Lancet. 2017;389(10069):655-666.

20. Adil SM, Liu B, Charalambous LT, Kiyani M, Gramer R, Swisher CB, et al. Healthcare Economics of Hydrocephalus After Aneurysmal Subarachnoid Hemorrhage in the United States. Transl Stroke Res. 2019;10(6):650-663.

21. Neifert SN, Chapman EK, Martini ML, Shuman WH, Schupper AJ, Oermann EK, et al. Aneurysmal Subarachnoid Hemorrhage: the Last Decade. Transl Stroke Res. 2020.

22. Connolly ES, Jr., Rabinstein AA, Carhuapoma JR, Derdeyn CP, Dion J, Higashida RT, et al. Guidelines for the management of aneurysmal subarachnoid hemorrhage: a guideline for healthcare professionals from the American Heart Association/american Stroke Association. Stroke. 2012;43(6):1711-1737.

23. Diringer MN, Bleck TP, Claude Hemphill J, 3rd, Menon D, Shutter L, Vespa P, et al. Critical care management of patients following aneurysmal subarachnoid hemorrhage: recommendations from the Neurocritical Care Society's Multidisciplinary Consensus Conference. Neurocrit Care. 2011;15(2):211-240.

24. Vergouwen MD, Vermeulen M, van Gijn J, Rinkel GJ, Wijdicks EF, Muizelaar JP, et al. Definition of delayed cerebral ischemia after aneurysmal subarachnoid hemorrhage as an outcome event in clinical trials and observational studies: proposal of a multidisciplinary research group. Stroke. 2010;41(10):2391-2395.

25. Lee SU, Hong EP, Kim BJ, Kim SE, Jeon JP. Delayed Cerebral Ischemia and Vasospasm After Spontaneous Angiogram-Negative Subarachnoid Hemorrhage: An Updated Meta-Analysis. World Neurosurg. 2018;115:e558-e569.

26. Badjatia N, Topcuoglu MA, Buonanno FS, Smith EE, Nogueira RG, Rordorf GA, et al. Relationship between hyperglycemia and symptomatic vasospasm after subarachnoid hemorrhage. Crit Care Med. 2005;33(7):1603-1609; quiz 1623.

27. Matano F, Fujiki Y, Mizunari T, Koketsu K, Tamaki T, Murai Y, et al. Serum Glucose and Potassium Ratio as Risk Factors for Cerebral Vasospasm after Aneurysmal Subarachnoid Hemorrhage. J Stroke Cerebrovasc Dis. 2019;28(7):1951-1957.

28. Black PH. Stress and the inflammatory response: a review of neurogenic inflammation. Brain Behav Immun. 2002;16(6):622-653.

29. Benedict CR, Loach AB. Clinical significance of plasma adrenaline and noradrenaline concentrations in patients with subarachnoid haemorrhage. J Neurol Neurosurg Psychiatry. 1978;41(2):113-117.

30. Ogura T, Satoh A, Ooigawa H, Sugiyama T, Takeda R, Fushihara G, et al. Characteristics and prognostic value of acute catecholamine surge in patients with aneurysmal subarachnoid hemorrhage. Neurol Res. 2012;34(5):484-490.

31. Chalouhi N, Daou B, Okabe T, Starke RM, Dalyai R, Bovenzi CD, et al. Beta-blocker therapy and impact on outcome after aneurysmal subarachnoid hemorrhage: a cohort study. J Neurosurg. 2016;125(3):730-736. 
32. Takemoto Y, Hasegawa Y, Hayashi K, Cao C, Hamasaki T, Kawano T, et al. The Stabilization of Central Sympathetic Nerve Activation by Renal Denervation Prevents Cerebral Vasospasm after Subarachnoid Hemorrhage in Rats. TransI Stroke Res. 2020;11(3):528-540.

33. Latorre JG, Chou SH, Nogueira RG, Singhal AB, Carter BS, Ogilvy CS, et al. Effective glycemic control with aggressive hyperglycemia management is associated with improved outcome in aneurysmal subarachnoid hemorrhage. Stroke. 2009;40(5):1644-1652.

34. Smith ML, von Hanwehr R, Siesjo BK. Changes in extra- and intracellular pH in the brain during and following ischemia in hyperglycemic and in moderately hypoglycemic rats. J Cereb Blood Flow Metab. 1986;6(5):574-583.

35. Huang YH, Chung CL, Tsai HP, Wu SC, Chang CZ, Chai CY, et al. Hyperglycemia Aggravates Cerebral Vasospasm after Subarachnoid Hemorrhage in a Rat Model. Neurosurgery. 2017;80(5):809-815.

36. Huang YH, Chung CL, Tsai HP, Tzou RD, Wu SC, Chai CY, et al. Impact of hyperglycemia on neuronal apoptosis after subarachnoid hemorrhage in rodent brain: An experimental research. Int $\mathrm{J}$ Surg. 2020;83:246-252.

37. Beseoglu K, Steiger HJ. Elevated glycated hemoglobin level and hyperglycemia after aneurysmal subarachnoid hemorrhage. Clin Neurol Neurosurg. 2017;163:128-132.

38. Schlenk F, Nagel A, Graetz D, Sarrafzadeh AS. Hyperglycemia and cerebral glucose in aneurysmal subarachnoid hemorrhage. Intensive Care Med. 2008;34(7):1200-1207.

39. Schlenk F, Graetz D, Nagel A, Schmidt M, Sarrafzadeh AS. Insulin-related decrease in cerebral glucose despite normoglycemia in aneurysmal subarachnoid hemorrhage. Crit Care. 2008;12(1):R9.

40. Schmutzhard E, Rabinstein AA, Participants in the International Multi-Disciplinary Consensus Conference on the Critical care Management of Subarachnoid H. Spontaneous subarachnoid hemorrhage and glucose management. Neurocrit Care. 2011;15(2):281-286.

41. Kinoshita K, Moriya T, Utagawa A, Sakurai A, Mukoyama T, Furukawa M, et al. Change in brain glucose after enteral nutrition in subarachnoid hemorrhage. J Surg Res. 2010;162(2):221-224.

42. Kofler M, Schiefecker AJ, Beer R, Gaasch M, Rhomberg P, Stover J, et al. Enteral nutrition increases interstitial brain glucose levels in poor-grade subarachnoid hemorrhage patients. J Cereb Blood Flow Metab. 2018;38(3):518-527.

\section{Tables}

Table 1 Characteristics of $\mathrm{DCl}$ and non-DCl groups 


\begin{tabular}{|c|c|c|c|}
\hline & Total $(n=24$ & & \\
\hline Variable & $\mathrm{DCl}(\mathrm{n}=62)$ & non-DCl $(n=182)$ & $P$ value \\
\hline Age, yr & $58.2 \pm 10.7$ & $54.9 \pm 11.2$ & 0.045 \\
\hline Gender, male & $35(56.5)$ & $101(55.5)$ & 0.896 \\
\hline Hypertension & $28(45.2)$ & $53(29.1)$ & 0.021 \\
\hline Alcohol & $21(33.9)$ & $73(40.1)$ & 0.383 \\
\hline Smoke & $20(32.3)$ & 68 (37.4) & 0.470 \\
\hline Hospital stay, d & $13(9.5-18)$ & $6(4-9)$ & $\nabla 0.001$ \\
\hline ICU stay & $48(77.4)$ & $95(52.2)$ & $\otimes 0.001$ \\
\hline PAN-SAH & 19 (30.6) & 145 (79.7) & $\otimes 0.001$ \\
\hline BMI, kg/区 & $23.9 \pm 2.9$ & $23.7 \pm 2.8$ & 0.548 \\
\hline WFNS & $2(1-4)$ & $1(1-1)$ & $\nabla 0.001$ \\
\hline $\mathrm{HH}$ grade & $2(2-3)$ & $2(1-2)$ & $\nabla 0.001$ \\
\hline $\mathrm{mFS}$ & $3(2-4)$ & $1(1-2)$ & $\nabla 0.001$ \\
\hline SEBES & $0(0-2)$ & $0(0-0)$ & $\nabla 0.001$ \\
\hline IVH & $27(43.5)$ & $27(14.8)$ & $\nabla 0.001$ \\
\hline Sodium, $\mathrm{mmol} / \mathrm{L}$ & $139.3 \pm 4.2$ & $139.0 \pm 3.3$ & 0.522 \\
\hline Potassium, mmol/L & $3.72 \pm 0.45$ & $3.81 \pm 0.38$ & 0.137 \\
\hline Glucose, $\mathrm{mmol} / \mathrm{L}$ & $8.78 \pm 2.39$ & $6.68 \pm 1.26$ & $\nabla 0.001$ \\
\hline $\mathrm{TC}, \mathrm{mmol} / \mathrm{L}$ & $4.75 \pm 1.00$ & $4.84 \pm 1.07$ & 0.602 \\
\hline $\mathrm{TG}, \mathrm{mmol} / \mathrm{L}$ & $1.46 \pm 0.72$ & $1.42 \pm 0.79$ & 0.699 \\
\hline $\mathrm{HDL}-\mathrm{C}, \mathrm{mmol} / \mathrm{L}$ & $1.32 \pm 0.35$ & $1.29 \pm 0.29$ & 0.516 \\
\hline LDL-C, mmol/L & $2.59 \pm 0.81$ & $2.68 \pm 0.81$ & 0.473 \\
\hline ApoA1, g/L & $1.20 \pm 0.24$ & $1.23 \pm 0.21$ & 0.529 \\
\hline ApoB, g/L & $0.91 \pm 0.28$ & $0.92 \pm 0.24$ & 0.739 \\
\hline Rebleeding & $6(9.7)$ & $0(0)$ & $\nabla 0.001$ \\
\hline Hydrocephalus & $13(21.0)$ & $4(2.2)$ & $\nabla 0.001$ \\
\hline Seizure & $2(3.2)$ & $1(0.5)$ & 0.325 \\
\hline
\end{tabular}




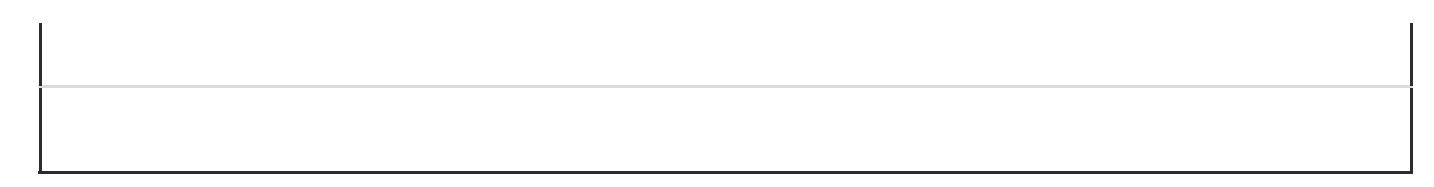

$\mathrm{DCl}$, delayed cerebral ischemia; PAN-SAH, perimesencephalic angiogram-negative subarachnoid hemorrhage; BMI, body mass index; WFNS, World Federation of Neurosurgeons Scale; HH, Hunt and Hess; mFS, modified Fisher scale; SEBES, Subarachnoid Hemorrhage Early Brain Edema Score; IVH, intraventricular hemorrhage; TC, total cholesterol; TG, triglyceride; HDL-C, high-density lipoprotein cholesterol; LDL-C, low-density lipoprotein cholesterol; ApoA1, apolipoprotein A1; ApoB, apolipoprotein B

Table 2 Comparison of variables between PAN-SAH and NPAN-SAH patients

\begin{tabular}{|c|c|c|c|}
\hline & Total $(n=244)$ & & \\
\hline Variable & PAN-SAH $(n=164)$ & NPAN-SAH $(n=80)$ & $P$ value \\
\hline Age, yr & $55.3 \pm 10.8$ & $56.7 \pm 11.9$ & 0.342 \\
\hline Gender, male & $86(52.4)$ & $50(62.5)$ & 0.137 \\
\hline Hypertension & $52(31.7)$ & $29(36.3)$ & 0.479 \\
\hline Hospital stay, d & $7(4-10.75)$ & $10(6-15)$ & $₫ 0.001$ \\
\hline ICU stay & $90(54.9)$ & $53(66.3)$ & 0.090 \\
\hline WFNS & $1(1-1)$ & $1(1-2)$ & $\varangle 0.001$ \\
\hline HH grade & $2(1-2)$ & $2(2-3)$ & $\nabla 0.001$ \\
\hline $\mathrm{mFS}$ & $1(1-1)$ & $4(2-4)$ & $₫ 0.001$ \\
\hline SEBES & $0(0-0)$ & $0.5(0-2)$ & $\varangle 0.001$ \\
\hline $\mathrm{IVH}$ & $24(14.6)$ & $30(37.5)$ & $\varangle 0.001$ \\
\hline Glucose, mmol/L & $6.92 \pm 1.68$ & $7.80 \pm 2.08$ & $\varangle 0.001$ \\
\hline $\mathrm{DCl}$ & 19 (11.6) & $43(53.8)$ & $\varangle 0.001$ \\
\hline Rebleeding & $0(0)$ & $6(7.5)$ & 0.001 \\
\hline Hydrocephalus & $3(1.8)$ & $14(17.5)$ & $₫ 0.001$ \\
\hline Seizure & $1(0.6)$ & $2(2.5)$ & 0.523 \\
\hline
\end{tabular}

PAN-SAH, perimesencephalic angiogram-negative subarachnoid hemorrhage; NPAN-SAH, nonperimesencephalic angiogram-negative subarachnoid hemorrhage; WFNS, World Federation of Neurosurgeons Scale; HH, Hunt and Hess; mFS, modified Fisher scale; SEBES, Subarachnoid Hemorrhage Early Brain Edema Score; IVH, intraventricular hemorrhage; DCl, delayed cerebral ischemia 
Table 3 Comparison of variables between $\mathrm{DCl}$ and non-DCl groups

Page 16/21 


\begin{tabular}{|c|c|c|c|c|c|c|}
\hline \multirow[b]{2}{*}{ Variable } & \multicolumn{3}{|c|}{ PAN-SAH $(n=164)$} & \multicolumn{3}{|c|}{ NPAN-SAH $(n=80)$} \\
\hline & $\mathrm{DCl}(\mathrm{n}=19)$ & $\begin{array}{l}\text { non-DCl } \\
(n=145)\end{array}$ & $\begin{array}{l}P \\
\text { value }\end{array}$ & $\mathrm{DCl}(\mathrm{n}=43)$ & $\begin{array}{l}\text { non-DCl } \\
(n=37)\end{array}$ & $\begin{array}{l}P \\
\text { value }\end{array}$ \\
\hline Age, yr & $58.4 \pm 10.2$ & $54.9 \pm 10.8$ & 0.182 & $58.1 \pm 11.0$ & $55.1 \pm 12.9$ & 0.259 \\
\hline Gender, male & $8(42.1)$ & 78 (53.8) & 0.337 & $27(62.8)$ & $23(62.2)$ & 0.954 \\
\hline Hypertension & $9(47.4)$ & $43(29.7)$ & 0.119 & 19 (44.2) & $10(27.0)$ & 0.111 \\
\hline Hospital stay, d & $12(10-16)$ & $6(4-9)$ & $\begin{array}{l}\square \\
0.001\end{array}$ & $14(8-19)$ & $6(4-10)$ & $\begin{array}{l}\square \\
0.001\end{array}$ \\
\hline ICU stay & 15 (78.9) & 75 (51.7) & 0.046 & 33 (76.7) & $20(54.1)$ & 0.032 \\
\hline WFNS & $2(1-3)$ & $1(1-1)$ & $\begin{array}{l}\square \\
0.001\end{array}$ & $2(1-4)$ & $1(1-1)$ & 0.001 \\
\hline $\mathrm{HH}$ grade & $2(2-2)$ & $2(1-2)$ & 0.043 & $2(2-4)$ & $2(1-2)$ & 0.005 \\
\hline $\mathrm{mFS}$ & $1(1-2)$ & $1(1-1)$ & 0.046 & $4(3-4)$ & $2(2-4)$ & 0.006 \\
\hline SEBES & $0(0-0)$ & $0(0-0)$ & 0.313 & $2(0-4)$ & $0(0-1)$ & 0.003 \\
\hline IVH & $6(31.6)$ & $18(12.4)$ & 0.026 & $21(48.8)$ & $9(24.3)$ & 0.024 \\
\hline \multicolumn{7}{|l|}{ Glucose, $\mathrm{mmol} / \mathrm{L}$} \\
\hline Day 1 & $8.93 \pm 2.56$ & $6.67 \pm 1.33$ & $\begin{array}{l}\square \\
0.001\end{array}$ & $8.72 \pm 2.34$ & $6.73 \pm 0.95$ & $\begin{array}{l}\square \\
0.001\end{array}$ \\
\hline Day 2 & $7.40 \pm 2.63$ & $5.81 \pm 1.48$ & $\stackrel{\square}{0.001}$ & $7.34 \pm 2.23$ & $6.12 \pm 1.28$ & 0.004 \\
\hline Day 3 & $6.92 \pm 1.73$ & $5.39 \pm 1.05$ & $\begin{array}{l}\square \\
0.001\end{array}$ & $6.92 \pm 1.92$ & $5.63 \pm 1.09$ & 0.001 \\
\hline $\begin{array}{l}\text { Mean of day } 4 \text { to } \\
\text { day } 5\end{array}$ & $7.25 \pm 2.53$ & $5.58 \pm 1.30$ & $\begin{array}{l}\square \\
0.001\end{array}$ & $7.00 \pm 2.06$ & $5.70 \pm 1.13$ & 0.001 \\
\hline $\begin{array}{l}\text { Mean of the first } \\
\text { three days }\end{array}$ & $7.75 \pm 2.01$ & $5.95 \pm 1.11$ & $\begin{array}{l}\square \\
0.001\end{array}$ & $7.66 \pm 1.90$ & $6.16 \pm 0.96$ & $\begin{array}{l}\square \\
0.001\end{array}$ \\
\hline Max & $9.30 \pm 2.60$ & $6.89 \pm 1.45$ & $\stackrel{\square}{0.001}$ & $9.13 \pm 2.40$ & $6.89 \pm 1.00$ & $\begin{array}{l}0.001 \\
0.01\end{array}$ \\
\hline Min & $6.40 \pm 1.95$ & $5.08 \pm 0.97$ & $\begin{array}{l}\square \\
0.001\end{array}$ & $6.49 \pm 1.73$ & $5.41 \pm 1.02$ & 0.001 \\
\hline Max-min & $\begin{array}{l}2.36(1.36- \\
3.92)\end{array}$ & $\begin{array}{l}1.60(1.09- \\
2.36)\end{array}$ & 0.037 & $\begin{array}{l}2.27(1.57- \\
3.55)\end{array}$ & $\begin{array}{l}1.43(0.98- \\
1.93)\end{array}$ & $\begin{array}{l}\square \\
0.001\end{array}$ \\
\hline $\begin{array}{l}\text { SD of the first three } \\
\text { days }\end{array}$ & $\begin{array}{l}0.92(0.61- \\
1.49)\end{array}$ & $\begin{array}{l}0.68(0.46- \\
0.91)\end{array}$ & 0.038 & $\begin{array}{l}0.92(0.62- \\
1.46)\end{array}$ & $\begin{array}{l}0.61(0.40- \\
0.83)\end{array}$ & 0.001 \\
\hline $\begin{array}{l}\text { CV of the first three } \\
\text { days }\end{array}$ & $\begin{array}{l}0.11(0.09- \\
0.16)\end{array}$ & $\begin{array}{l}0.11(0.09- \\
0.15)\end{array}$ & 0.687 & $\begin{array}{l}0.13(0.09- \\
0.19)\end{array}$ & $\begin{array}{l}0.11(0.06- \\
0.15)\end{array}$ & 0.050 \\
\hline
\end{tabular}




\begin{tabular}{|c|c|c|c|c|c|c|}
\hline Day 1-day 2 & $\begin{array}{l}1.31(0.39- \\
1.71)\end{array}$ & $\begin{array}{l}0.76(0.21- \\
1.58)\end{array}$ & 0.227 & $\begin{array}{l}1.15(0.43- \\
2.29)\end{array}$ & $\begin{array}{l}0.38(-0.09- \\
1.30)\end{array}$ & 0.012 \\
\hline Day 1-day 3 & $\begin{array}{l}1.46(1.00- \\
2.91)\end{array}$ & $\begin{array}{l}1.20(0.77- \\
1.61)\end{array}$ & 0.118 & $\begin{array}{l}1.48(0.83- \\
2.95)\end{array}$ & $\begin{array}{l}1.10(0.53- \\
1.79)\end{array}$ & 0.048 \\
\hline $\begin{array}{l}\text { (Day 1-day 2)/day } \\
1 * 100 \%\end{array}$ & $\begin{array}{l}15.5(5.6- \\
21.3)\end{array}$ & $\begin{array}{l}11.6(3.3- \\
23.1)\end{array}$ & 0.760 & $\begin{array}{l}13.5(3.9- \\
25.9)\end{array}$ & $\begin{array}{l}6.3(-1.3- \\
19.4)\end{array}$ & 0.057 \\
\hline $\begin{array}{l}\text { (Day 1-day 3)/day } \\
1 * 100 \%\end{array}$ & $\begin{array}{l}19.2(10.1- \\
27.0)\end{array}$ & $\begin{array}{l}18.8(12.9- \\
23.8)\end{array}$ & 0.785 & $\begin{array}{l}19.4(10.5- \\
31.1)\end{array}$ & $\begin{array}{l}17.3(8.1- \\
25.0)\end{array}$ & 0.245 \\
\hline
\end{tabular}

PAN-SAH, perimesencephalic angiogram-negative subarachnoid hemorrhage; NPAN-SAH, nonperimesencephalic angiogram-negative subarachnoid hemorrhage; $\mathrm{DCl}$, delayed cerebral ischemia; WFNS, World Federation of Neurosurgeons Scale; HH, Hunt and Hess; mFS, modified Fisher scale; SEBES, Subarachnoid Hemorrhage Early Brain Edema Score; IVH, intraventricular hemorrhage; Max, maximum; Min, minimum; SD, standard deviation; CV, coefficient of variation

Table 4 Univariate and multivariate logistic regression analysis of predictors for $\mathrm{DCl}$ 


\begin{tabular}{|c|c|c|c|c|}
\hline & Univariate analysis & & Multivariate analysis & \\
\hline Variable & OR $(95 \% \mathrm{Cl})$ & $P$ value & OR $(95 \% \mathrm{Cl})$ & $P$ value \\
\hline \multicolumn{5}{|l|}{ PAN-SAH } \\
\hline Age, yr & $1.033(0.985-1.083)$ & 0.182 & & \\
\hline Gender, male & $0.625(0.237-1.644)$ & 0.341 & & \\
\hline Admission glucose, $\mathrm{mmol} / \mathrm{L}$ & $1.862(1.402-2.473)$ & $\varangle 0.001$ & $1.705(1.232-2.360)$ & 0.001 \\
\hline SD of the first three days & $3.163(1.428-7.006)$ & 0.005 & & \\
\hline WFNS grade & $3.738(1.873-7.461)$ & $₫ 0.001$ & $2.889(1.322-6.311)$ & 0.008 \\
\hline $\mathrm{HH}$ grade & $3.101(1.268-7.585)$ & 0.013 & & \\
\hline mFS grade & $1.830(1.099-3.048)$ & 0.02 & $1.658(0.875-3.141)$ & 0.121 \\
\hline SEBES score & $1.456(0.854-2.480)$ & 0.167 & & \\
\hline IVH & $3.256(1.099-9.647)$ & 0.033 & & \\
\hline \multicolumn{5}{|l|}{ NPAN-SAH } \\
\hline Age, yr & $1.022(0.984-1.062)$ & 0.258 & & \\
\hline Gender, male & $1.027(0.414-2.546)$ & 0.954 & & \\
\hline Admission glucose, $\mathrm{mmol} / \mathrm{L}$ & $3.257(1.748-6.067)$ & $\varangle 0.001$ & $2.307(1.167-4.562)$ & 0.016 \\
\hline SD of the first three days & $8.202(2.241-30.026)$ & 0.001 & $5.684(1.006-32.114)$ & 0.049 \\
\hline WFNS grade & $2.103(1.316-3.359)$ & 0.002 & $1.550(0.863-2.786)$ & 0.143 \\
\hline $\mathrm{HH}$ grade & $2.402(1.334-4.324)$ & 0.003 & & \\
\hline mFS grade & $1.810(1.170-2.800)$ & 0.008 & $1.859(1.051-3.288)$ & 0.033 \\
\hline SEBES score & $1.772(1.225-2.564)$ & 0.002 & $1.443(0.894-2.328)$ & 0.133 \\
\hline IVH & $2.970(1.137-7.756)$ & 0.026 & & \\
\hline
\end{tabular}

$\mathrm{DCl}$, delayed cerebral ischemia; PAN-SAH, perimesencephalic angiogram-negative subarachnoid hemorrhage; NPAN-SAH, non-perimesencephalic angiogram-negative subarachnoid hemorrhage; SD, standard deviation; WFNS, World Federation of Neurosurgeons Scale; HH, Hunt and Hess; mFS, modified Fisher scale; SEBES, Subarachnoid Hemorrhage Early Brain Edema Score; IVH, intraventricular hemorrhage; $\mathrm{OR}$, odds ratio; $\mathrm{Cl}$, confidence interval

\section{Figures}


PAN-SAH

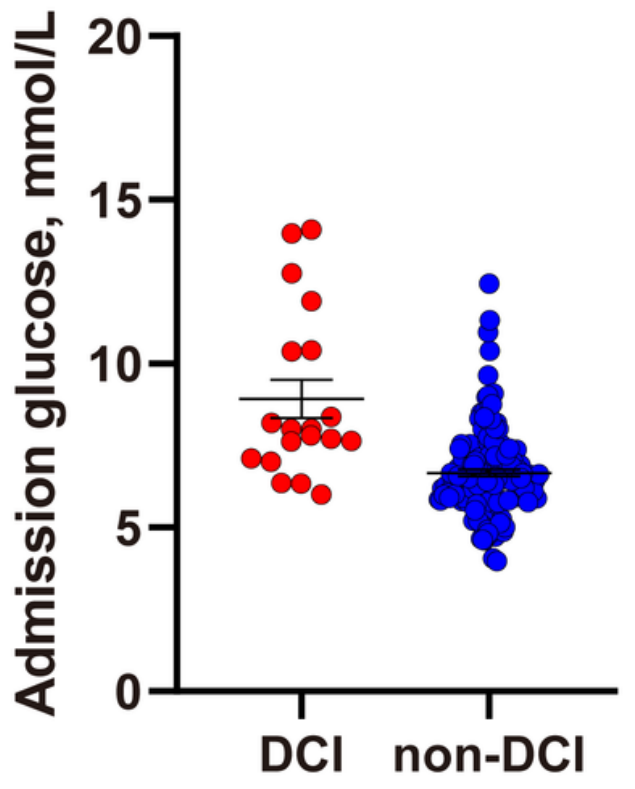

C

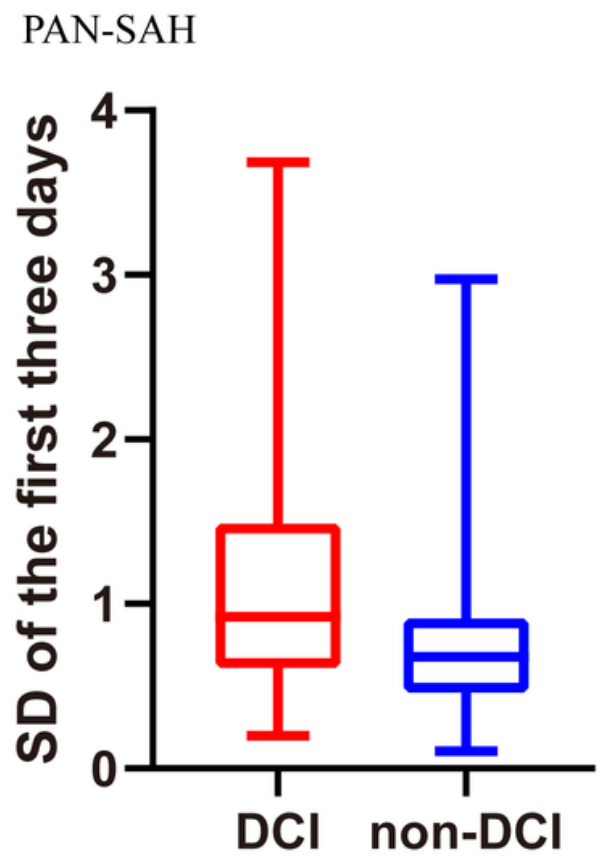

NPAN-SAH

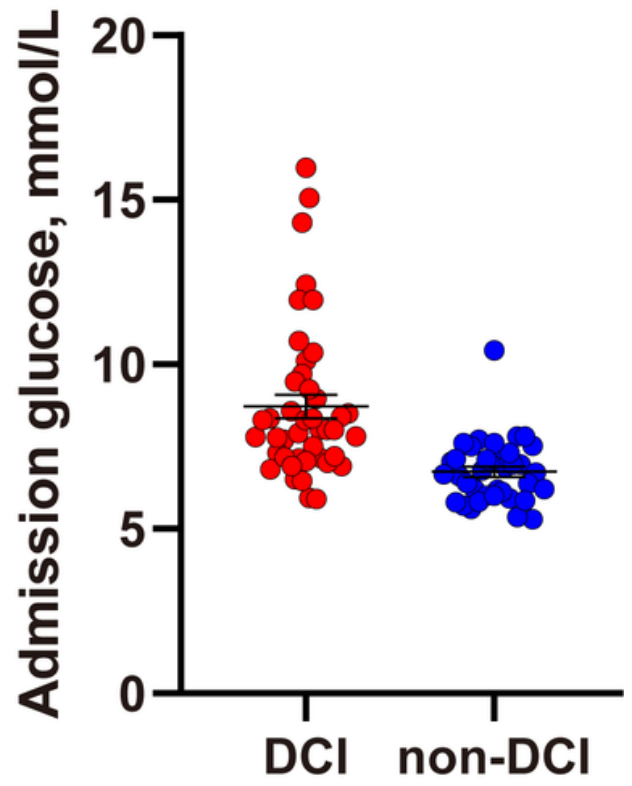

$\mathrm{D}$

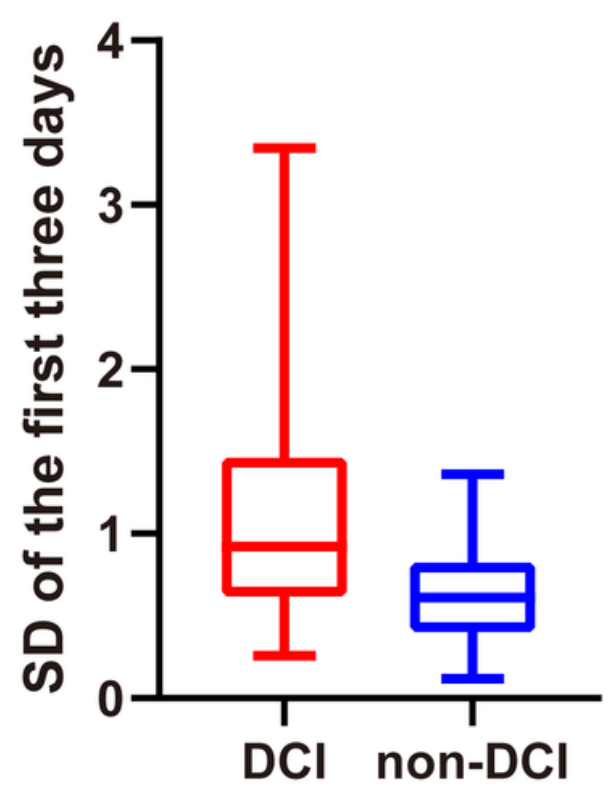

Figure 1

Comparisons of admission glucose and SD of serum glucose in the first three days between DCl and non$\mathrm{DCl}$ groups. DCl group was significantly related to higher admission serum glucose than non-DCl group in both PAN-SAH $(A, p<0.001)$ and NPAN-SAH $(B, p<0.001)$ patients. There was a significant association between high SD of serum glucose in the first three days and DCl group in both PAN-SAH (C, $p=0.038)$ and NPAN-SAH ( $D, p=0.001$ ) patients. SD, standard deviation; DCl, delayed cerebral ischemia; PAN-SAH, perimesencephalic angiogram-negative subarachnoid hemorrhage; NPAN-SAH, non-perimesencephalic angiogram-negative subarachnoid hemorrhage 
A

PAN-SAH

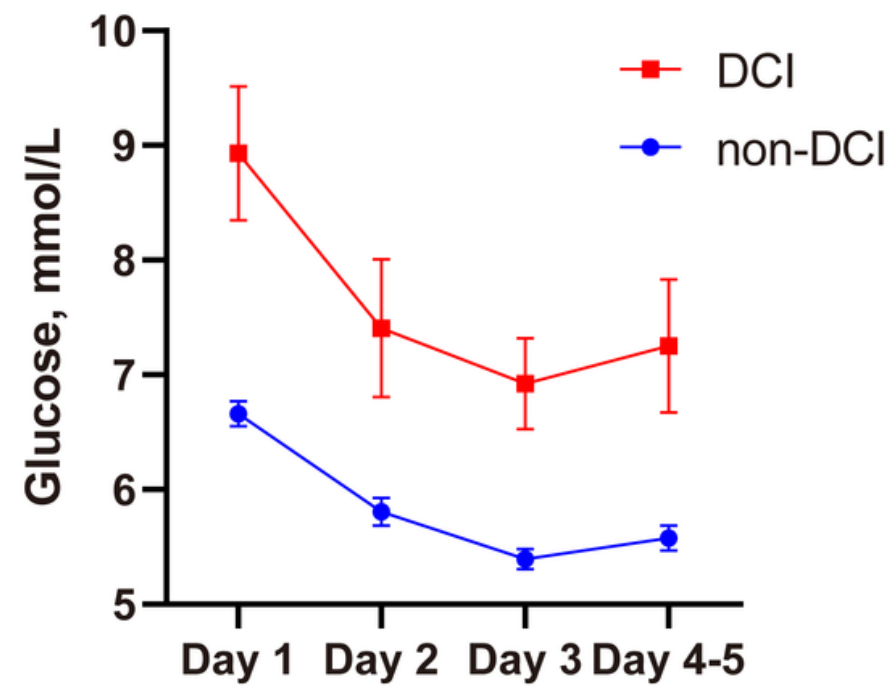

B

NPAN-SAH

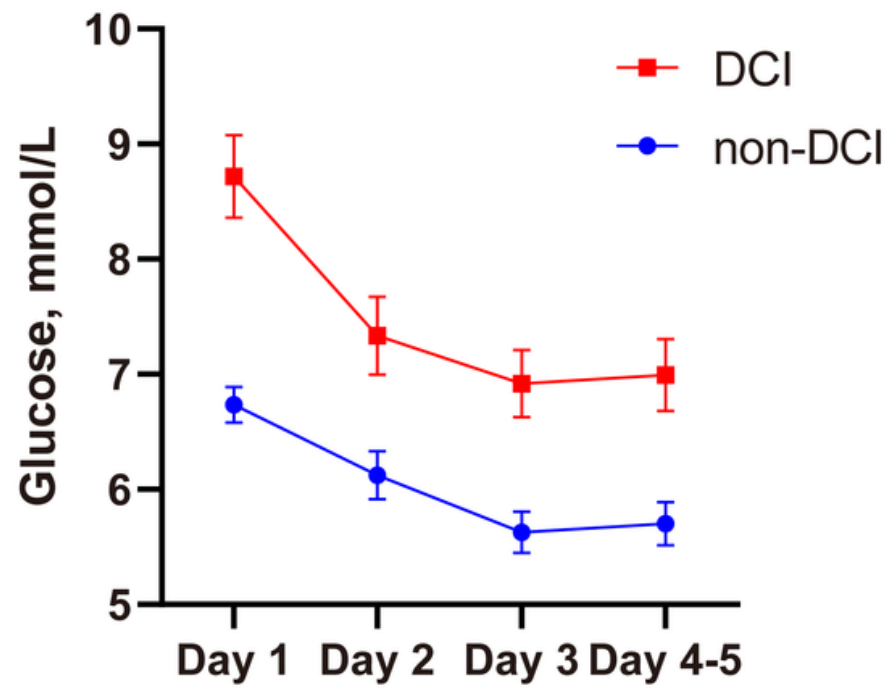

Figure 2

Dynamic changes of serum glucose after admission. Serum glucose of $\mathrm{DCl}$ and non-DCl groups showed a similar trend in both PAN-SAH (A) and NPAN-SAH (B) patients, reaching the lowest value on the third day after admission. In both two populations, the serum glucose of $\mathrm{DCl}$ group was consistently higher than that of non-DCl group in the first five days after admission. DCl, delayed cerebral ischemia; PAN-SAH, perimesencephalic angiogram-negative subarachnoid hemorrhage; NPAN-SAH, non-perimesencephalic angiogram-negative subarachnoid hemorrhage

\section{Supplementary Files}

This is a list of supplementary files associated with this preprint. Click to download.

- Additionalfile1Tables1.docx

- Additionalfile2Figures1.tif 